\title{
Reasons for the Lack of Salutary Effects of Cholesterol-Lowering Interventions in End-Stage Renal Disease Populations
}

\author{
Nosratola D. Vaziri ${ }^{a}$ Keith C. Norris ${ }^{b}$ \\ a Departments of Medicine, Physiology and Biophysics, Division of Nephrology and Hypertension, University of \\ California, Irvine, Calif., and ${ }^{b}$ Charles R. Drew University of Medicine and Science, Los Angeles, Calif., USA
}

\section{Key Words}

Statins · Lipid disorders • Cardiovascular disease •

Progression of kidney disease $\cdot$ Hemodialysis $\cdot$ Nephrotic syndrome

\begin{abstract}
Cardiovascular disease (CVD) is the main cause of premature death in patients with chronic kidney disease (CKD). The underlying mechanisms of CVD in patients with mild to moderate CKD are different from those with end-stage renal disease (ESRD). While serum cholesterol is frequently elevated and contributes to atherosclerosis in many CKD patients, particularly those with nephrotic proteinuria, it is usually normal, even subnormal, in most ESRD patients receiving hemodialysis. CVD in the ESRD population is primarily driven by oxidative stress, inflammation, accumulation of the oxidation-prone intermediate-density lipoproteins, chylomicron remnants and small dense low-density lipoprotein particles as well as high-density lipoprotein deficiency and dysfunction, hypertension, vascular calcification, and arrhythmias. Only a minority of hemodialysis patients have hypercholesterolemia which is most likely due to genetic or unrelated factors. In addition, due to peritoneal losses of proteins which simulate nephrotic syndrome, peritoneal dialysis patients often exhibit hypercholesterolemia. Clearly when present, hypercholesterolemia contributes to CVD in the CKD and ESRD population and justifies cholesterol-lowering
\end{abstract}

therapy. However, the majority of ESRD patients and a subpopulation of CKD patients with minimal proteinuria have normal or subnormal serum cholesterol levels and do not benefit from and can be potentially harmed by statin therapy. In fact the lack of efficacy of statins in hemodialysis patients has been demonstrated in several randomized clinical trials. This review is intended to provide an overview of the mechanisms responsible for the failure of statins to reduce cardiovascular morbidity and mortality in most ESRD patients and to advocate the adoption of individualized care principles in the management of dyslipidemia in this population.

Copyright $\odot 2013$ S. Karger AG, Basel

\section{Introduction}

HMG-CoA reductase inhibitors (statins) are highly effective in reducing the risk of ischemic cardiovascular events in the general population [1]. Since chronic kidney disease (CKD) is associated with a marked increase in the incidence of premature death from ischemic and nonischemic cardiovascular diseases (CVD), it was assumed that statin therapy may be similarly effective in this population. However, large randomized clinical trials designed to explore the efficacy of statins in patients with end-stage renal disease (ESRD) have failed to show any benefit [2-4]. This is not surprising since serum choles-

\section{KARGER}

Fax +4161306 1234

E-Mail karger@karger.ch

www.karger.com (c) 2013 S. Karger AG, Basel

0253-5068/13/0353-0031\$38.00/0

Accessible online at:

www.karger.com/bpu
N.D. Vaziri, MD, MACP

Division of Nephrology and Hypertension

University of California, Irvine Medical Center

Suite 400, The City Tower, Orange, CA 92868 (USA)

E-Mail ndvaziri@uci.edu 
terol level is normal or subnormal in the majority of these patients. In fact, serum cholesterol level is inversely related to mortality in this population [5]. The accelerated atherosclerosis and CVD in the majority of these patients is not due to elevated low-density lipoprotein (LDL) cholesterol. It is instead due to accumulation of highly atherogenic oxidation-prone intermediate-density lipoprotein (IDL), chylomicron remnants, and small dense LDL particles together with high-density lipoprotein (HDL) deficiency and dysfunction, oxidative stress and inflammation. These abnormalities are not caused by increased cholesterol biosynthesis or its elevated serum concentration and as such are not amenable to cholesterol-lowering interventions [6]. In fact, by blocking the formation of highly essential intermediary and alternative by-products of the mevalonate metabolism, use of HMG-CoA reductase inhibitors can lead to adverse consequences which can potentially raise the overall morbidity and mortality [7]. This review is intended to provide a brief overview of the biological reason behind the failure of the clinical trials of statins in reducing the cardiovascular morbidity and mortality in the majority of ESRD patients and to advocate the adoption of individualized care principles in the management of dyslipidemia in this population.

\section{Effect of Statins in Primary Prevention of CVD in ESRD Patients}

Three large prospective randomized clinical trials have been conducted to determine the efficacy of different statins in reducing the risk of CVD in hemodialysis patients. The first among these trials was the 4D (Die Deutsche Diabetes Dialyse) study [2]. This study enrolled 1,255 hemodialysis patients with type 2 diabetes randomized to receive atorvastatin $(20 \mathrm{mg} /$ day $)$ or placebo for 4 years. The study revealed no reduction in the risk of either death from cardiac causes or non-fatal MI. On the contrary, the study showed a significant increase in the risk of fatal stroke in the statin-treated patients.

The second trial was AURORA (A Study to Evaluate the Use of Rosuvastatin in Subjects on Regular Hemodialysis: An Assessment of Survival and Cardiovascular Events) which was a double-blind, randomized, placebocontrolled trial designed to compare the impact of rosuvastatin (10 mg/day) against placebo on cardiovascular morbidity and mortality in hemodialysis patients [3]. The study enrolled 2,776 hemodialysis patients aged 50-80 years with a mean baseline LDL cholesterol concentra- tion of about $100 \mathrm{mg} / \mathrm{dl}$. The mean duration of treatment was 2.4 years and the mean length of follow-up was 3.2 years. During the study period, close to 1,300 patients died and over 800 patients discontinued the treatment as a result of either adverse drug reactions or kidney transplantation. Despite an impressive $43 \%$ reduction in serum LDL cholesterol, rosuvastatin therapy failed to reduce the incidence of major cardiovascular events including fatal and non-fatal myocardial infarction or overall mortality. In fact the drug significantly increased the rate of fatal hemorrhagic stroke in diabetic patients $(\mathrm{p}=0.03)$, confirming the finding of the 4D study.

The third large randomized statin trial in patients with kidney disease was SHARP (the Study of Heart And Renal Protection) [4] which differed from the 4D and AURORA trials in that it included 3,023 dialysis patients and a large cohort of 6,247 CKD patients not requiring dialysis with an average estimated glomerular filtration rate of $27 \mathrm{ml} / \mathrm{min} / 1.73 \mathrm{~m}^{2}$. The enrolled patients were randomized to receive simvastatin $20 \mathrm{mg} /$ day with or without ezetimibe $10 \mathrm{mg} /$ day or placebo. The median duration of follow-up in this trial was 4.9 years. The trial intended to determine the efficacy of LDL cholesterol reduction on major atherosclerotic event including death due to coronary disease, myocardial infarction, nonhemorrhagic stroke, or need for revascularization procedures and the rate of decline in renal function in the CKD patients. The study showed $17 \%$ reduction in major atherosclerotic events, $25 \%$ reduction in non-hemorrhagic stroke, $21 \%$ reduction in coronary revascularization and a trend toward reduction in non-fatal myocardial infarction in the simvastatin- and ezetimibe-treated group. However, as with the 4D and AURORA studies, cholesterol-lowering therapy failed to reduce either mortality rates or cardiovascular events in the dialysis patients enrolled in the SHARP trial. Thus the favorable effects reported in this study were due to the inclusion of a large cohort of patients with less advanced CKD in whom the pathophysiology of CVD more closely resembles that of the general population than the hemodialysis patients.

\section{Effect of Statins in Hypercholesterolemic ESRD Patients and CKD Population}

In contrast to the majority of hemodialysis patients in whom statin therapy fails to show any benefit, post hoc analysis of data from the $4 \mathrm{D}$ trial has revealed a significant reduction of CV events and overall mortality with statin therapy in the subpopulation of patients who had 
significant hypercholesterolemia [8]. Likewise, as described in recent reviews and meta-analyses of numerous clinical trials, cholesterol-lowering interventions have proven effective in reducing the risk of atherosclerotic $\mathrm{CV}$ events in the CKD population not requiring dialysis $[6,9,10]$. In addition, several studies have shown the efficacy of statins in retarding progression of CKD and reducing the magnitude of proteinuria in CKD population [11-17]. The exception is rosuvastatin which due to its high concentration and that of its metabolites in the kidney can raise proteinuria and worsen renal function particularly when given at high doses [18]. The salutary effects of statins in CKD patients are described in a review article by Campese [19] published in the current issue of this journal and will not be addressed here.

\section{Reasons for Ineffectiveness of Statins in the Majority of Hemodialysis Patients}

As mentioned above, serum cholesterol is normal or subnormal in the majority of hemodialysis patients and HMG-CoA reductase expression and activity are normal in the liver and markedly suppressed in the kidney and vascular tissues of uremic animals [20-22]. The primary cause of atherosclerosis and CVD in this population is oxidative stress, inflammation [23-25], HDL deficiency and dysfunction [26-28], accumulation of IDL and chylomicron remnants, and the presence of small dense LDL [29]. These abnormalities cannot be corrected by inhibiting cholesterol synthesis. In addition, disturbances of calcium and phosphate metabolism, hypertension, arrhythmogenic electrolyte disorders, hypervolemia, uremic toxins, anemia, comorbid conditions such as diabetes, etc. contribute to CVD in this population which are likewise unrelated to cholesterol metabolism and are not amenable to statin administration. The differences in the disturbances in cholesterol metabolism between earlier stages of CKD, particularly when accompanied by nephrotic proteinuria and advanced $\mathrm{CKD}$, contribute to the divergent response to statin therapy. A brief description of the effects of these conditions on lipid metabolism is provided below.

\section{Effect of Different Stages of Kidney Disease on Cholesterol Metabolism}

Glomerular proteinuria is a common feature of many, but not all, forms of progressive kidney diseases. When present, nephrotic proteinuria results in hypercholester- olemia which contributes to the high risk of atherosclerotic CVD. This is caused by acquired hepatic LDL receptor deficiency [30] and HDL docking receptor deficiency $[31,32]$ which promote hypercholesterolemia by: (i) limiting hepatic clearance of circulating LDL- and HDL-borne cholesterol and (ii) stimulating hepatic cholesterol biosynthesis via upregulation of HMG-CoA reductase expression and activity in response to a diminished influx of cholesterol via LDL and HDL receptors. Thus, reduced clearance and increased production of cholesterol by the liver work in concert to promote hypercholesterolemia in patients and animals with nephrotic proteinuria [33]. The associated hypercholesterolemia, in turn, promotes atherosclerotic CVD and contributes to lipotoxicity and progression of kidney disease [22, 34, 35]. It is therefore not surprising that inhibition of HMG-CoA reductase confers cardiovascular and renal protection in such patients. In most cases the decline in glomerular filtration rate with progression to ESRD would inevitably result in marked reduction and eventually cessation of filtered proteins and hence proteinuria. This, in turn, leads to reversal of LDL and HDL receptor deficiencies and the resulting hypercholesterolemia. In fact, hepatic LDL receptor and HDL docking receptor abundance and HMGCoA reductase expression and activity are normal in uremic animals $[21,36]$. This accounts for the absence of hypercholesterolemia and lack of salutary effect of statins in most ESRD patients.

\section{Effect of CKD on Triglyceride and ApoB-Containing Lipoprotein Metabolism}

Despite having normal, even subnormal, serum cholesterol levels, patients with ESRD are at an extremely high risk of atherosclerosis, arteriosclerosis and CVD. This is, in part, due to accumulation of oxidation-prone and highly atherogenic ApoB-containing lipoproteins, i.e. IDL, small dense LDL (containing ApoB100) and chylomicron remnants (containing ApoB48) which are avidly engulfed by macrophages leading to their transformation to foam cells in the artery walls. This is occasioned by CKD-induced deficiencies of lipoprotein lipase and VLDL receptor in skeletal muscles and adipose tissues [37-40] and of triglyceride lipase in the liver [41, 42]. Normally, lipoprotein lipase removes two thirds of the fatty acid contents of VLD for delivery to the muscle tissue for production of energy and to the adipose tissue for storage of energy leading to transformation of VLDL to IDL. IDL is then transformed to cholesterol-rich LDL by 
disposal of its remaining triglyceride content and acquisition of cholesterol. This process is mediated by: (i) partial exchange of IDL's triglyceride cargo for the mature HDL's cholesterol contents via cholesterol ester transfer protein - as described below, advanced CKD results in impairment of cholesterol-rich HDL formation which contributes to defective maturation of IDL to LDL, and (ii) hydrolysis of all the IDL's remaining triglyceride cargo by hepatic triglyceride lipase. Likewise chylomicrons which serve as the vehicle for delivery of the dietary lipid cargo to the sites of consumption and storage are processed by lipoprotein lipase and hepatic triglyceride lipase forming remnant particles that are normally cleared by a multifunctional receptor known as LDL receptorrelated protein (LRP). Expression of LRP is markedly reduced in the liver of animals and most likely humans with advanced CKD [43]. The CKD-induced LRP deficiency accounts for prolonged postprandial hyperglycemia and accumulation of chylomicron remnants in patients with advanced CKD or ESRD. Together, by inducing lipoprotein lipase, hepatic triglyceride lipase and LRP deficiencies and impairing formation of cholesterol-rich HDL particles advanced CKD results in accumulation of atherogenic IDL and chylomicron remnants which promote atherosclerosis. In addition, via oxidation chain reaction and immune activation, accumulation of these remnant particles in the circulation contributes to dissemination of oxidative stress and inflammation in advanced CKD/ESRD. The disturbances of triglyceride and ApoB-containing lipoproteins described above are not directly linked to cholesterol synthesis or its serum concentration and as such are not amenable to statin therapy.

\section{Effect of CKD on HDL Metabolism}

Serum HDL cholesterol is commonly reduced and the ratio of cholesterol ester-poor HDL3 to cholesterol esterrich HDL2 is increased in the great majority of patients with ESRD and a subset of patients with CKD who have little or no proteinuria. Several factors contribute to reduction of HDL, its cholesterol contents, and impaired maturation from HDL3 to HDL2 in these populations. These include: (i) downregulation of hepatic expression/ production of ApoA1 which is the principal apoprotein constituent of HDL [36, 44-46]; (ii) increased expression and activity of acyl-CoA:cholesterol acyltransferase-1 (ACAT) which catalyzes esterification of cholesterol and promotes foam cell formation in the artery wall and kidney $[47,48]$ thereby favoring retention of cholesterol within the cells and limiting release of free cholesterol for uptake by HDL; (iii) oxidative modification of HDL which impairs its ability to bind ATP binding cassette-A1 on the surface of cholesterol-laden cells in the artery wall and kidney [27, 49-51], a process which is essential for uptake of cholesterol by HDL, commonly referred to as reverse cholesterol transport; (iv) reduced hepatic production and hence abundance and activity of lecithincholesterol acyltransferase (LCAT) [52], an HDL-associated enzyme which is essential for esterification of free cholesterol on the surface of the nascent HDL; the LCATmediated esterification of cholesterol leads to its translocation from the surface to the core of HDL, a process that is necessary for maximum uptake of cholesterol from the cholesterol-laden cells and maturation of HDL, and (v) removal and degradation of HDL by the liver via HDL endocytic receptor (ATP synthase $\beta$ ) which binds and internalizes cholesterol ester-poor HDL particles. This contrasts the hepatic HDL docking receptor (SRB1) which reversibly binds cholesterol ester-rich HDL enabling unloading of its cholesterol ester cargo and hydrolysis and removal of its triglyceride content followed by release of the unloaded HDL to repeat the cycle. Since as noted above most HDL particles are cholesterol ester-poor, they are predisposed to undergo endocytosis and degradation in the liver. These abnormalities work in concert to lower serum HDL and its cholesterol content and impair HDLmediated reverse cholesterol transport. Once again, these disturbances are not due to increased cholesterol synthesis and as such are not amenable to statin therapy.

\section{Side Effects of Statins}

In addition to the intended inhibition of cholesterol production, HMG-CoA reductase inhibitors block the synthesis of by-products of alternative (i.e. ubiquinone and dolichols) and intermediary (e.g. farnesyl-pyrophosphate and geranylgeranyl-pyrophosphates) pathways of mevalonate metabolism. These products have major biological functions and as such their reduced bioavailability can lead to adverse consequences. For instance, farnesylpyrophosphate and geranylgeranyl-pyrophosphate are essential for prenylation of proteins which is necessary for transport of newly synthesized proteins between endoplasmic reticulum and Golgi apparatus as well as regulation of cell growth and gene transcription. In addition, dolichols are involved in production of glycoproteins which are necessary for tissue growth, whereas ubiquinone (Coenzyme Q10) is necessary for mitochondrial 
electron transport and oxidative phosphorylation. By limiting the biosynthesis of these products, statins can potentially cause mitochondrial dysfunction and disrupt intracellular traffic, signal transduction, gene transcription, and production of structural proteins [7]. These unintended effects are responsible for the statin-induced myopathy and liver injury among other systemic complications. cies leads to increased cholesterol synthesis and hypercholesterolemia and an increased risk of atherosclerotic CVD and CKD progression. Clearly, statins are highly effective in reducing cardiovascular events and retarding CKD progression in such patients. Likewise, subpopulations of ESRD patients who exhibit hypercholesterolemia due to genetic and other disorders can benefit from cholesterol-lowering interventions.

\section{Acknowledgments}

The majority of patients with ESRD maintained on hemodialysis and subpopulation of CKD patients who have little to no proteinuria have normal, even subnormal, serum cholesterol levels. Statin therapy in such patients confers no benefit and can, in fact, lead to adverse consequences. This contrasts the CKD population with significant glomerular proteinuria which by inducing acquired LDL receptor and HDL docking receptor deficien-
This work is supported in part by NIH grants U54MD007598 (K.C.N., N.D.V.), UL1RR033176 (K.C.N.), and P20MD000182 (K.C.N.).

\section{Disclosure Statement}

The authors have no conflicts of interest to disclose.

\section{References}

$>1$ Baigent C, Keech A, Kearney PM, Blackwell L, Buck G, Pollicino C, Kirby A, Sourjina T, Peto R, Collins R, Simes R; Cholesterol Treatment Trialists' (CTT) Collaborators: Efficacy and safety of cholesterol-lowering treatment: prospective meta-analysis of data from 90,056 participants in 14 randomized trials of statins. Lancet 2005;366:1267-1278.

$\checkmark 2$ Wanner C, Krane V, Marz W, et al: Atorvastatin in patients with type 2 diabetes mellitus undergoing hemodialysis. $\mathrm{N}$ Engl J Med 2005;353:238-248.

-3 Fellstrom BC, Jardine AG, Schmieder RE, et al: Rosuvastatin and cardiovascular events in patients undergoing hemodialysis. N Engl J Med 2009;360:1395-1407.

$>4$ Baigent C, Landray MJ, Reith C, et al: The effects of lowering LDL cholesterol with simvastatin plus ezetimibe in patients with chronic kidney disease (Study of Heart And Renal Protection): a randomized placebocontrolled trial. Lancet 2011;377:2181-2192.

$>5$ Kilpatrick RD, McAllister CJ, Kovesdy CP, Derose SF, Kopple JD, Kalantar-Zadeh K: Association between serum lipids and survival in hemodialysis patients and impact of race. J Am Soc Nephrol 2007;18:293-303.

$\checkmark 6$ Epstein M, Vaziri ND: Role of statins in the management of dyslipidemia of chronic kidney disease: current concepts and emerging treatment paradigms. Nat Rev Nephrol 2012; $8: 214-223$.
7 Beltowski J, Wójcicka G, Jamroz-Wisniewska A: Adverse effects of statins - mechanisms and consequences. Current Drug Safety 2009;4:209-228.

-8 März W, Genser B, Drechsler C, Krane V, Grammer TB, Ritz E, Stojakovic T, Scharnagl $\mathrm{H}$, Winkler $\mathrm{K}$, Holme I, Holdaas $\mathrm{H}$, Wanner C, on behalf of the German Diabetes and Dialysis Study Investigators: Atorvastatin and low-density lipoprotein cholesterol in type 2 diabetes mellitus patients on hemodialysis. Clin J Am Soc Nephrol 2011; 1316-1325.

$\checkmark 9$ Upadhyay A, Earley A, Lamont JL, Haynes S, Wanner C, Balk EM: Lipid-lowering therapy in persons with chronic kidney disease: a systematic review and meta-analysis. Ann Intern Med 2012;157:251-262.

10 Palmer SC, Craig JC, Navaneethan SD, Tonelli M, Pellegrini F, Strippoli GF: Benefits and harms of statin therapy for persons with chronic kidney disease: a systematic review and meta-analysis. Ann Intern Med 2012; 157:263-275.

11 Collins R, Armitage J, Parish S, Sleigh P, Peto R; Heart Protection Study Collaborative Group: MRC/BHF Heart Protection Study of cholesterol-lowering with simvastatin in 5,963 people with diabetes: a randomised placebo-controlled trial. Lancet 2003;361: 2005-2016.
-12 Athyros VG, Mikhailidis DP, Papageorgiou AA, et al: The effect of statins versus untreated dyslipidaemia on renal function in patients with coronary heart disease. A subgroup analysis of the Greek Atorvastatin and Coronary Heart Disease Evaluation (GREACE) study. J Clin Pathol 2004;57:728734.

13 Tonelli M, Moye L, Sacks FM, et al: Effect of pravastatin on loss of renal function in people with moderate chronic renal insufficiency and cardiovascular disease. J Am Soc Nephrol 2003;14:1605-1613.

14 Shepherd J, Kastelein JJ, Bittner V, et al: Effect of intensive lipid lowering with atorvastatin on renal function in patients with coronary heart disease: the Treating to New Targets (TNT) study. Clin J Am Soc Nephrol 2007;2:1131-1139.

15 Fried LF, Orchard TJ, Kasiske BL: Effect of lipid reduction on the progression of renal disease: a meta-analysis. Kidney Int 2001;59: 260-269.

16 Sandhu S, Wiebe N, Fried LF, Tonelli M: Statins for improving renal outcomes: a meta-analysis. J Am Soc Nephrol 2006; 17: 2006-2016.

17 Douglas K, O’Malley PG, Jackson JL: Metaanalysis: the effect of statins on albuminuria. Ann Intern Med 2006;145:117-124.

18 http://clinicaltrials.gov/ct2/show/NCT0029 6400 ?term=planet\&rank=1;http://clinicaltrials.gov/ct2/show/NCT00296374?term=pl anet\&rank=2. 
$\checkmark 19 \mathrm{Ku}$ E, Campese V: Is lipid management effective for all stages of CKD? Blood Purif 2013;35:26-30.

20 Vaziri ND: Dyslipidemia of chronic renal failure: the nature, mechanisms and potential consequences. Am J Physiol Renal Physiol 2006;290:262-272.

21 Liang K, Vaziri ND: Gene expression of LDL receptor, HMG-CoA reductase and cholesterol-7 $\alpha$-hydroxylase in chronic renal failure. Nephrol Dial Transplant 1997;12:13811386.

22 Kim HJ, Moradi H, Vaziri ND: Renal mass reduction results in accumulation of lipids and dysregulation of lipid regulatory proteins in the remnant kidney. Am J Physiol Renal Physiol 2009;296:F1297-F1306.

23 Himmelfarb J, Stenvinkel P, Ikizler TA, Hakim R: The elephant in uremia: oxidant stress as a unifying concept of cardiovascular disease in uremia. Kidney Int 2002;62: 1524-1538.

24 Stenvinkel P, Alvestrand A: Inflammation in end-stage renal disease: sources, consequences, and therapy. Semin Dial 2002;15: 329-337.

25 Vaziri ND: Oxidative stress in chronic renal failure: the nature, mechanism and consequences. Semin Nephrol 2004;24:469-473.

26 Vaziri ND, Navab M, Fogelman AM: HDL metabolism and activity in chronic kidney disease. Nat Rev Nephrol 2010;6:287-296.

-27 Kalantar-Zadeh K, Kopple JD, Kamranpour N, Fogelman AM, Navab M: HDL inflammatory index correlates with poor outcome in hemodialysis patients. Kidney Int 2007; 72:1149-1156.

28 Vaziri ND, Moradi H, Pahl MV, Fogelman AM, Navab M: In vitro stimulation of HDL anti-inflammatory activity and inhibition of LDL pro-inflammatory activity in the plasma of patients with end-stage renal disease by an ApoA-1 mimetic peptide. Kidney Int 2009;76:437-444

29 Vaziri ND, Norris K: Lipid disorders and their relevance to outcomes in chronic kidney disease. Blood Purif 2011;31:189-196.
30 Vaziri ND, Liang K: Downregulation of hepatic LDL receptor expression in experimental nephrosis. Kidney Int 1996;50:887-893.

31 Liang K, Vaziri ND: Down-regulation of hepatic high-density lipoprotein receptor, SRB-1, in nephrotic syndrome. Kidney Int 1999;56:621-626

32 Vaziri ND, Gollapudi P, Han S, Farahmand G, Moradi H: Upregulation of hepatic HDL endocytic receptor and PDZK-1-dependent downregulation of HDL docking receptor in nephrotic syndrome. Nephrol Dial Transplant 2011;103:524-533.

33 Vaziri ND: Molecular mechanisms of lipid dysregulation in nephrotic syndrome. Kidney Int 2003;63:1964-1976.

34 Moorhead JF, Chan MK, El-Nahas M, et al: Lipid nephrotoxicity in chronic progressive glomerular and tubulo-interstitial disease. Lancet 1982;2:1309-1311.

35 Vaziri ND: Lipotoxicity and impaired HDLmediated reverse cholesterol/lipid transport in chronic kidney disease. J Renal Nutr 2010; 20:S35-S43.

36 Vaziri ND, Deng G, Liang K: Hepatic HDL receptor, SR-B1 and ApoA-I expression in chronic renal failure. Nephrol Dial Transplant 1999;14:1462-1466.

37 Akmal M, Kasim SE, Soliman AR, Massry SG: Excess parathyroid hormone adversely affects lipid metabolism in chronic renal failure. Kidney Int 1990;37:854-858.

38 Vaziri ND, Liang K: Down-regulation of tissue lipoprotein lipase expression in experimental chronic renal failure. Kidney Int 1996;50:1928-1935.

39 Vaziri ND, Wang XQ, Liang K: Secondary hyperparathyroidism downregulates lipoprotein lipase expression in chronic renal failure. Am J Physiol Renal Physiol 1997; 273:F925-F930.

40 Vaziri ND, Yuan J, Ni Z, Nicholas SB, Norris, KC: Lipoprotein lipase deficiency in chronic kidney disease is compounded by downregulation of endothelial GPIHBP1 expression. Clin Exp Nephrol 2012;16:238-243.

41 Klin M, Smogorzewski M, Ni Z, Zhang G, Massry SG: Abnormalities in hepatic lipase in chronic renal failure: role of excess parathyroid hormone. J Clin Invest 1996;97: 2167-2173.
42 Liang K, Vaziri ND: Downregulation of hepatic lipase expression in experimental nephrotic syndrome. Kidney Int 1997;51:19331937.

43 Kim C, Vaziri ND: Downregulation of hepatic LDL receptor-related protein in chronic renal failure. Kidney Int 2005;67:10281032.

44 Attman PO, Alaupovic P: Lipid and apolipoprotein profiles of uremic dyslipoproteinemia - relation to renal function and dialysis. Nephron 1991;57:401-410.

45 Vaziri ND, Deng G, Liang K: Hepatic HDL receptor, SR-B1 and Apo A-I expression in chronic renal failure. Nephrol Dial Transplant 1999;14:1462-1466.

46 Kamanna VS, Kashyap ML, Pai R, et al: Uremic serum subfraction inhibits apolipoprotein A-I production by a human hepatoma cell line. J Am Soc Nephrol 1994;5:193-200.

47 Liang K, Vaziri ND: Upregulation of acylCoA: cholesterol acyltransferase in chronic renal failure. Am J Physiol 2002;283:E676E681.

48 Moradi H, Yuan J, Ni Z, Norris K, Vaziri ND Reverse cholesterol transport pathway in experimental chronic kidney disease. Am J Nephrol 2009;30:147-154

49 Vaziri ND, Navab M, Fogelman AM: HDL metabolism and activity in chronic kidney disease. Nat Rev Nephrol 2010;6:287-296.

50 Moradi H, Pahl MV, Elahimehr R, Vazir ND: Impaired antioxidant activity of highdensity lipoprotein in chronic kidney disease. Transl Res 2009;153:77-78.

-51 Vaziri ND, Moradi H, Pahl MV, Fogelman AM, Navab M: In vitro stimulation of HDL anti-inflammatory activity and inhibition of LDL pro-inflammatory activity in the plasma of patients with end-stage renal disease by an ApoA-1 mimetic peptide. Kidney Int 2009;76:437-444.

52 Vaziri ND, Liang K, Parks JS: Downregulation of hepatic lecithin: cholesterol acyltransferase gene expression in chronic renal failure. Kidney Int 2001;59:2192-2196. 